\title{
Effects of Augmented Reality (AR) Game on Human Health
}

\author{
Sai L NG* and Ben MA \\ Department of Geography and Resource Management, The Chinese University, Hong Kong
}

*Corresponding author: Sai L NG, Department of Geography and Resource Management, The Chinese University of Hong Kong, Shatin, New Territories, Hong Kong.

To Cite This Article: Sai L NG.Effects of Augmented Reality (AR) Game on Human Health. Am J Biomed Sci \& Res. 2019 - 6(2). AJBSR.MS.ID.001012. DOI: 10.34297/AJBSR.2019.06.001012.

Received: 㠿 November 08, 2019; Published: 眥 November 14, 2019

\author{
Abstract \\ The Augmented Reality (AR) game, Pokémon GO, has the potential to improve human health on a global scale. This paper reviews the effects of AR \\ game on players' physical, mental, and social health.
}

Keywords: Augmented Reality (AR) Game; Pokémon GO; Human Health; Physical Health; Mental Health; Social Health

\section{Introduction}

Playing game is important to humans. Game players learn knowledge, acquire living capabilities, and enjoy the excitement through playing game. In the old days, people focused on physical games. Thanks to the advancement of computer technology, both hardware and software, electronic and video games globally had attracted a very large population of people [1]. These games were often accused of causing negative impacts, such as physical inactivity and game addiction, on human health. Nowadays, 60$85 \%$ of people in the world lead a sedentary lifestyle [2]. However, the success of Pokémon GO showed that Augmented Reality (AR) game, a new type of game, has the potential to change the sedentary lifestyle of game players and improve their health on a global scale. According to the World Health Organization (WHO) in its constitution, health can be defined as "a state of complete physical, mental, and social well-being and not merely the absence of disease or infirmity" [3]. This paper aims to provide a short review of the effects of AR game on players' physical, mental, and social health.

\section{The Wave of AR Game}

$\mathrm{AR}$ is an experience that real-world objects are enhanced by computer-generated virtual information. Applying the AR technique in game design, Pokémon GO requires players to travel to various locations of the real world in order to capture unique virtual characters (i.e., Pokémon) or treasures. By May 2017, one year after the launch of Pokémon GO, 9\% of the global population had installed the game and the players had traveled a total distance of more than 15.8 billion km [4]. Following the step of Pokémon GO, many AR games were released in last 3 years, e.g., The Walking Dead Our World, Jurassic World Alive, Let's Hunt Monsters, Harry Potter: Wizard Unite, and Dragon Quest Walk. More AR games are forth-coming, e.g., Minecraft Earth, CATAN World Explorers. One common element of these games is the mobilization of players to search virtual objects in the real world based on the geographical information provided. As these new games have been steadily gaining popularity, they are generating a new wave of influence on human health.

\section{Physical Health and AR Game}

Existing literature indicated a positive influence of AR game on physical activity levels of the game players. An Asian study reported that the average daily walking and running distances increased by $0.96 \mathrm{~km}$ in the first month after the players installed Pokémon GO compared with the average distances before installation [5]. Other studies in the United States reported that players increased their daily walking activities by a range of 955 to 1473 steps on average, a more than $20 \%$ increase compared with their prior activity level $[6,7]$. However, the association between Pokémon GO and physical activity varies among different populations [8,9]. The game seems 
to be more attractive to males than to females [6] and to be more appealing to youths than to other age groups [5]. Furthermore, Pokémon GO's impact on walking attenuated over time and disappeared after playing the game for 24 days [5]. The finding was consistent with the fact that the number of people actively playing dropped within a month of the game's release [10]. Other AR games, e.g., Let's Hunt Monsters, and Harry Potter: Wizard Unite, also showed a similar decreasing pattern of popularity. The short life span is the major obstacle for AR game to generate continuous impacts on players' physical health.

\section{Mental Health and AR Game}

On one hand, AR games, like other games in general that have the component of making fun, are believed to generate positive impacts on players' happiness and emotional satisfaction [11]. On the other hand, AR games are different from other games because they demand players to travel to different locations in the real world. Therefore, players would have the opportunity to explore the environment and meet other people or players there. These traveling experiences would directly or indirectly make positive contributions to players' mental well-being [12]. A few studies had attempted to examine the association of playing AR game and players' mental health. Significant correlations were found between playing Pokémon Go and various positive responses, such as increased positive affect, and nostalgic reverie, etc. [13]. Further, playing the game could bring positive impacts on players' emotional wellness which predicted enhanced overall well-being [14]. However, the reasons why playing AR game associated with players' mental health has not yet been fully explored.

\section{Social Health and AR Game}

Very few studies have examined the relationship between playing AR game and players' social health. Social well-being of a person refers to the harmonious relationship with others and the capacity of making contribution to the community [15]. For most AR games, the game design includes a strong social component. Take Pokémon Go as an example, cooperation is rewardable as players are often required to form teams to hurt powerful Pokémons, which are very difficult to be captured by individual players. Theoretically, the gameplay would strengthen existing friendships and encourage to make new friends. However, the correlation between playing Pokémon and social well-being was not statistically significant [14]. Nevertheless, the social nature of AR games facilitates the formation of player networks, both locally and internationally. Network members use Telegram, Discord, WhatsApp and other SNS social media to share not only the game information but also other information about their lives. The phenomenon demonstrates that AR game can enhance real-life social interaction, which denotes a social media trend back toward networking in the real world [16].

\section{Conclusions}

The advancement of computer technology enables AR game to generate multi-dimensional effects on human health. Existing literature has already told us about the coming of this new era. However, further studies are needed to expand our understanding of these positive effects of AR game and extend the effects to a longer period.

\section{Conflict of Interest}

The Author and Co-author declare no conflict of interest.

\section{References}

1. Vorderer P, Hartmann T, Klimmt C (2003) Explaining the enjoyment of playing video games: The role of competition. Proceedings of the Second International Conference on Entertainment Computing, Pittsburgh, Pennsylvania, USA. p. 8-10.

2. World Health Organization (2002) Physical inactivity a leading cause of disease and disability, warns WHO.

3. World Health Organization (1948) Constitution of the World Health Organization

4. The Pokémon GO team (2017) Adventures Await! Pokémon GO.

5. Ma BD, Ng SL, Schwanen T, Zacharias J, Zhou M, et al. (2018) Pokémon GO and physical activity in Asia: Multilevel study. Journal of Medical Internet Research 20(6): e217.

6. Howe KB, Suharlim c, Ueda P, Howe D, Kawachi I, et al. (2016) Gotta catch'em all! Pokémon GO and physical activity among young adults: Difference in differences study. BMJ Clinical Research 355: 16270.

7. Althoff T, White RW, Horvitz E (2016) Influence of Pokémon Go on physical activity: Study and implications. Journal of Medical Internet Research 18(12): e315.

8. Nigg CR, Mateo DJ, An J (2017) Pokémon GO May Increase Physical Activity and Decrease Sedentary Behaviors. American Journal of Public Health 107(1): 37-38.

9. Wong FY (2017) Influence of Pokémon Go on physical activity levels of university players: A cross-sectional study. International Journal of Health Geographics 16: 8.

10. Evangelista B (2016) Is "Pokémon Go" gone? Data says interest is waning. San Francisco Chronicle.

11. Granic I, Lobel A, Engels RC (2014) The benefits of playing video games. American Psychologist 69(1): 66-78.

12. McCabe S, Johnson S (2013) The happiness factor in tourism: subjective well-being and social tourism. Annals of Tourism Research 41: 42-65.

13. Bonus JA, Peebles A, Mares ML, Sarmiento IG (2018) Look on the bright side (of media effects): Pokémon Go as a catalyst for positive life experiences. Media Psychology 21(2): 263-287.

14. Nikou S, Tarvoll J, Öörni A (2018) Impact of playing Pokémon go on wellness. Proceedings of the 51st Hawaii International Conference on System Sciences.

15. Keyes CLM (1998) Social Well-Being. Social Psychology Quarterly 61(2): 121-140.

16. Aluri A (2017) Mobile augmented reality (MAR) game as a travel guide: insights from Pokémon GO. Journal of Hospitality and Tourism Technology 8(1): 55-72 